\title{
A Sidestep Cut Preparation Strategy Decreases the External Load Applied to the Knee Joint
}

\author{
Kenji Kimura $^{1}$ and Shinji Sakurai ${ }^{2}$ \\ ${ }^{1}$ Graduate School of Health and Sport Sciences, Chukyo University, \\ 101 Tokodachi, Kaizu-cho, Toyota, Aichi, 470-0390 Japan \\ ${ }^{2}$ Faculty of Health and Sport Sciences, Chukyo University, \\ 101 Tokodachi, Kaizu-cho, Toyota, Aichi, Japan 470-0390 \\ E-mail: allegrisc@gmail.com \\ [Received March 21, 2013; Accepted October 23, 2013; Published online November 1, 2013]
}

\begin{abstract}
In the present study, we aimed to investigate the joint moments applied to the cutting leg (CL) knee during the sidestep cut and during the final step before cutting (BC) at slow and fast speeds. Seven male university basketball players performed a sidestep cut $60^{\circ}$ to the left, at fast (FAST, $80 \%$ of the maximum running speed) and slow (SLOW, $50 \%$ of the maximum running speed) speeds. The impulse of the mean anterior-posterior component of the ground reaction force and the peak external flexion moment of the BC knee during the FAST task were significantly larger than those during the SLOW task $\left(0.54 \pm 0.27 \mathrm{Ns} \cdot \mathrm{kg}^{-1}\right.$ vs. $0.12 \pm 0.27 \mathrm{Ns} \cdot \mathrm{kg}^{-1}, P<0.05$, and $3.16 \pm 0.64 \mathrm{Nm} \cdot \mathrm{kg}^{-1} \mathrm{vs.} 2.69 \pm 0.42 \mathrm{Nm} \cdot \mathrm{kg}^{-1}, P<0.05$, respectively). The peak external valgus moment of the knee during the first half of the CL stance was also significantly larger during the FAST task than during the SLOW task $\left(1.85 \pm 0.56 \mathrm{Nm} \cdot \mathrm{kg}^{-1}\right.$ vs. $0.95 \pm 0.57 \mathrm{Nm} \cdot \mathrm{kg}^{-1}$, $P<0.05)$. The peak external flexion moment of the CL knee joint did not significantly differ between the FAST and SLOW tasks. The external load applied to the knee joint could be decreased by avoiding the combination of an external valgus moment and an internal extension moment of the CL knee. Therefore, BC deceleration during a high-speed sidestep cut is an effective strategy for decreasing the external load on the CL knee joint.
\end{abstract}

Keywords: final step before cutting, deceleration, joint moments, running speed

\section{Introduction}

Changes in the direction of movement frequently occur during sporting activities, such as basketball and soccer. Previous studies have shown that changing direction, landing after jumping, and decelerating rapidly may cause a mechanical load on the knee; this load is potentially capable of causing anterior cruciate ligament (ACL) injuries (Cerulli et al., 2003; Chappell et al., 2005; Dufek and Bates, 1991; Pflum et al., 2004). Agel et al. (2005) reported that approximately $65 \%$ of ACL injuries occur as a result of noncontact events while playing basketball and soccer. Others (Cerulli et al., 2003) have suggested that the peak ACL tensile force is generated during the first-contact phase of rapid deceleration, during which the peak vertical ground reaction force (GRF) is also simultaneously generated. Besier et al. (2001a, 2001b) showed that there is a large deceleration component of the GRF during the first $25 \%$ of the contact phase during a sidestep cut, and that the external valgus-varus loads applied to the knee joint are significantly larger than those involved while running straight. Further, in vivo results have shown that a large ACL tensile force is generated when the knee is flexed more than $10^{\circ}$ and that the knee load is combined with the anterior tibial force and the external valgus moment (Markolf et al., 1995). This ACL tensile force was reported to be 1.5-2.0 times larger than that exerted when only an anterior tibial force was applied to the knee.

Although an ACL injury may occur suddenly, athletes can adopt safer movement patterns that reduce the risk of injury while changing directions, landing after jumping, or decelerating rapidly (Besier et al., 2001a, 2001b; Besier et al., 2003; Cowley et al., 2006; Hewett et al., 2002; Wojtys et al., 2003). Besier et al. (2001b, 2003) investigated the $30^{\circ}$ - and $60^{\circ}$-sidestep cutting maneuvers under preplanned and unanticipated conditions. They found that during unanticipated conditions, the external valgus and internal tibial rotation loads of the 
knee joint were significantly larger than those under preplanned conditions during the sidestep cut movement; under unanticipated conditions, a runner had less time to establish his posture for the sidestep cut. Thus, a preparatory strategy may be beneficial for reducing knee joint loads. However, there have been few examinations of planned movements during the sidestep cut. Therefore, the present study focused on how sidestep cuts are planned one step before the cut, and the effect of the preparatory strategy on knee joint loads during the sidestep cut while running.

Many studies have examined the effects of direction change movements on knee joint loads while running at a specific speed and when landing after jumping; these studies have focused on the joint angles and moments of the lower leg (Besier et al., 2001a, 2001b; Besier et al., 2003; Chappell et al., 2005; Kimura and Sakurai, 2008; Malinzak et al., 2001; McLean et al., 2004 a; Munro et al., 1987; Yu et al., 2006). However, the effects of running speed on knee loading during the sidestep cut has seldom been investigated. Olsen et al. (2004) determined that the injury rate may be influenced by the speed at which an athlete performs a cutting movement, given that most noncontact ACL injuries occur during high-velocity movements. Previous studies have shown that rapid deceleration increases the load on the ACL (Cerulli et al., 2003; Pflum et al., 2004). However, as previously noted, using a preparatory movement may be beneficial in reducing knee joint loads. The present study investigated movement adjustments during the final step before cutting (BC), i.e., the step immediately before the cut, for a preparatory movement at both slow and fast speeds. We quantified the angles and moments applied to the cutting leg $(\mathrm{CL}$; the leg opposite the direction of the cut) at both slow and fast speeds due to observe the effect of the preparatory strategy at the BC on the load applied to the CL knee joint. We hypothesized that the preparatory strategy at the BC decreases the load applied to the CL knee joint.

\section{Methods}

\subsection{Subjects and experimental design}

Seven male university basketball players (average age, $19.4 \pm 0.7$ years; average height, $1.80 \pm 0.07 \mathrm{~m}$; average body mass, $77.4 \pm 18.2 \mathrm{~kg}$ ), without any history of lower limb injury, volunteered for this investigation. Their mean basketball playing experience was $8.4 \pm 0.7$ years. Prior to data collection, the testing protocols were explained to the subjects and informed written consent was obtained, in accordance with the Declaration of Helsinki and the ethics requirements of Chukyo University.

The subjects were asked to perform a 40-m straight run with maximum effort. The time to complete the final $5 \mathrm{~m}$ was measured using 2 pairs of photocells (Multi-PAS; DKH, Tokyo, Japan), and this time was designated as the "maximum" speed for each subject. For this study, a "fast" speed was defined as $80 \%$ of the maximum speed and "slow" speed was $50 \%$ of the maximum speed; a deviation of $\pm 10 \%$ from the required speed was permitted.

The experimental setup is shown in Figure 1. All subjects were instructed to run from the starting line to the goal, which involved a sidestep cut of $60^{\circ}$ to the left, at both a fast (FAST) and a slow (SLOW) speed. In this study, we designated the right leg, which changes the running direction, as the $\mathrm{CL}$ and the left leg as the $\mathrm{BC}$ leg, which comes into contact

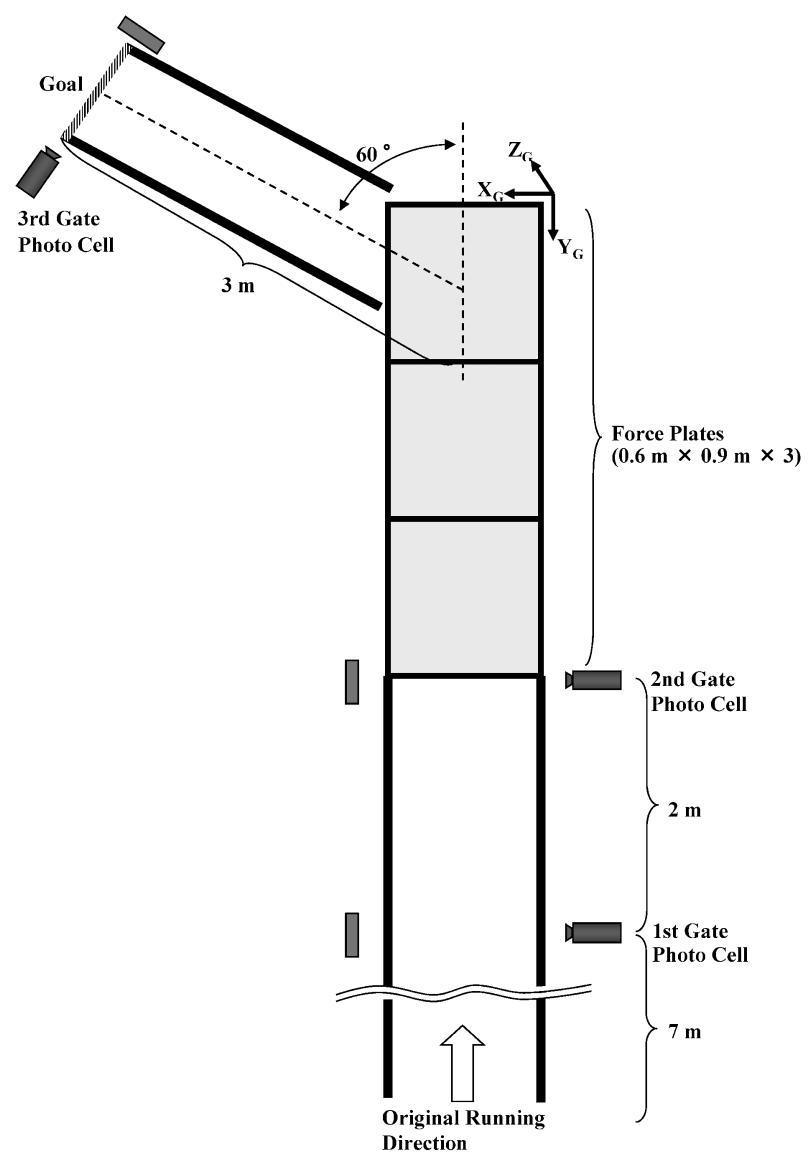

Figure 1 Experimental setup. 
with the ground immediately before the CL. Two pairs of photocells (first gate and second gate, Figure 1) were used to monitor the approach speed before the $\mathrm{BC}$ comes into contact with the ground during the maneuver. After changing direction, the subjects were instructed to complete the run to the goal at maximum speed. All subjects wore their own basketball shoes during the experiment. If a subject stepped over the experimental course line during a task, that trial was counted as a failure.

Forty-three retro-reflective markers were placed on body landmarks to record three-dimensional (3D) whole-body movements using a Vicon motion analysis system (Vicon MX, 10 cameras; Oxford Metrics, Oxford, United Kingdom). Kinematic data were collected at $250 \mathrm{~Hz}$. Three $0.6 \times 0.9-\mathrm{m}$ forceplatforms (Type 9287B; Kistler, Winterthur, Switzerland) were mounted in the middle of the experimental course. GRF data were collected as the subjects ran across the force platforms, and were sampled at $1 \mathrm{kHz}$. GRF and kinematic data collections were synchronized.

The subjects performed practice runs to become accustomed to the required speed and the footstrike, without any stride adjustment. We measured the time between the second and third gates using 2 pairs of photocells (Figure 1). Three successful trials were recorded for both the FAST and SLOW tasks. The fastest of the 3 successful trials for each task was used for the analysis.

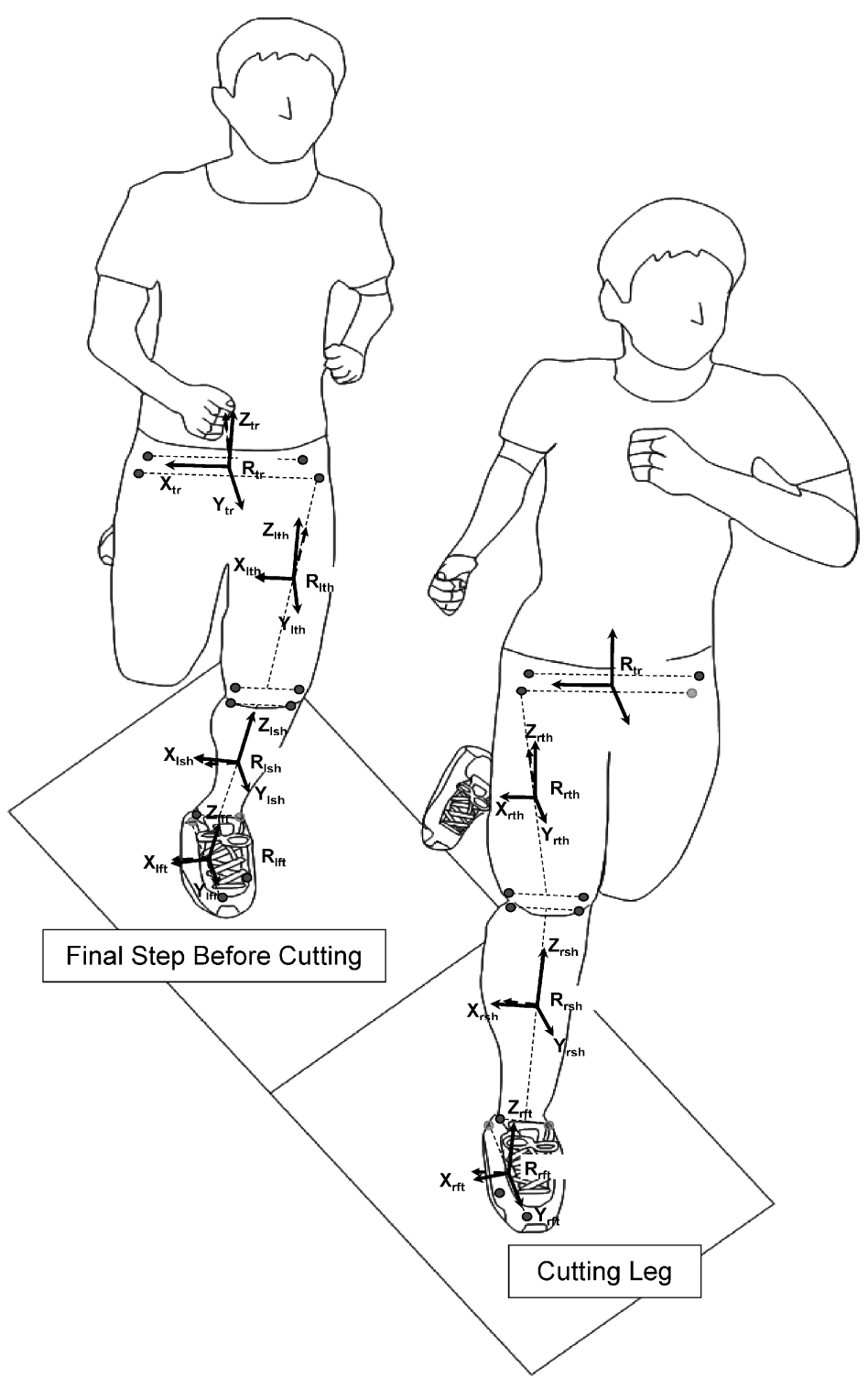

Figure 2 The segment coordinate systems for the trunk $\left(R_{t r}\right)$, thighs $\left(R_{r t h}, R_{l t h}\right)$, shins $\left(R_{r s h}, R_{l s h}\right)$, and feet $\left(R_{r f t}\right.$, $\mathrm{R}_{\mathrm{lft}}$ ), defined for each leg coming in contact with the ground. 
The raw data for the whole-body markers were filtered using a fourth-order, zero-lag, Butterworth, digital low-pass filter. The cutoff frequencies for the markers were determined to be $14-16 \mathrm{~Hz}$, using the optimum cutoff frequency method (Yu et al., 1999). The locations of the center of mass (COM) of each body segment and the body segment parameters were determined based on the estimated coefficients reported by Ae (1996) for Japanese athletes.

\subsection{Kinematics}

For this study, we defined a right-handed global coordinate system $R_{\mathrm{g}}$. The origin of this system was set at the right front edge of the third force platform. The $Y_{g}$ axis was defined as being horizontal and pointing along the opposite direction from the original running direction. The $\mathrm{Z}_{\mathrm{g}}$ axis was defined as being vertically upward, and the $\mathrm{X}_{\mathrm{g}}$ axis was defined as the cross product of the $\mathrm{Y}_{\mathrm{g}}$ and $\mathrm{Z}_{\mathrm{g}}$ axes (Figure 1). Based on the attached markers, we defined a rigid segment model for the lower leg, consisting of 7 body parts (trunk and the right and left thighs, shins, and feet). A right-handed Cartesian coordinate system was embedded in the trunk segment $\left(R_{t r}\right)$, the right lower leg segments $\left(R_{r t h}, R_{r s h}\right.$, and $\left.R_{r f t}\right)$, and the left lower leg segments $\left(R_{1 t h}, R_{1 s h}\right.$, and $R_{l f t}$ ) (Figure 2). To specify the $3 \mathrm{D}$ orientation and motion of each segment, Cardan angles were applied to describe the relative rotation of one segment with respect to another reference segment in the $3 \mathrm{D}$ space. The sequence of the Cardan rotations of the body-embedded systems was of the X-Y'- $\mathrm{Z}^{\prime \prime}$ type. Moreover, the knee joint (flexion-extension and valgus-varus) angles were calculated. The running speed for the whole body COM was also calculated.

\subsection{GRF data}

The BC and CL GRFs for each task (FAST and SLOW) were measured. The impulse of the anteriorposterior component of the GRF $\left(G R F_{y}\right)$, in the $R_{g}$ embedded in the force platform (Figure 1), and the duration of the foot contact were obtained for both the BC and CL. During the CL foot contact, the runner kicked (cut) the ground, and the GRFy was divided into the braking force and the propulsive force. The braking force acts on the body to minimize the velocity during the $\mathrm{CL}$ foot contact, and is followed by the propulsive force. To examine the braking force's effect on the body, we calculated the $\mathrm{GRF}_{\mathrm{y}}$ impulse from the initial CL foot contact to the minimum velocity point, defined by the resultant velocity curve for the COM (CL in the deceleration phase) (Kimura and Sakurai, 2008). And we also calculated the $\mathrm{GRF}_{\mathrm{y}}$ impulse during the $\mathrm{BC}$ foot contact. The free moment of the GRF and the location of the GRF center of pressure were determined; each leg segment was assumed to be a rigid body moving in accordance with Newton's laws (Andrews, 1974). The $\mathrm{GRF}_{\mathrm{y}}$ impulse was normalized to the subject's body mass.

\subsection{Kinetics}

Figure 3 shows each defined joint coordinate system. The moments for the knee joint (flexionextension and valgus-varus) were calculated using Vicon Body Builder (Oxford Metrics). The external moments were as previously described; for example, an external knee valgus moment abducts the knee and an external knee flexion moment flexes the knee (Besier et al., 2001a, 2001b; Hewett et al., 2005). The joint moments were normalized to the subject's body mass.

\subsection{Statistical analysis}

Paired $t$-tests were used to assess the significant differences between the FAST and SLOW running speeds, $\mathrm{GRF}_{\mathrm{y}}$ impulses, duration of foot contact, knee joint angles, and knee joint moments related to the BC and CL. The significance level was set to 5\% for all statistical analyses.

\section{Results}

Table 1 shows the comparative results for each variable between the FAST and SLOW tasks. The average running speeds at the time of the BC's initial contact (IC) with the ground, during the FAST and SLOW tasks, were $5.83 \pm 0.32 \mathrm{~m} \cdot \mathrm{s}^{-1}$ and $4.49 \pm$ $0.42 \mathrm{~m} \cdot \mathrm{s}^{-1}$, respectively $(P<0.05)$. The average running speeds at the CL's IC with the ground, during the FAST and SLOW tasks, were $5.51 \pm 0.32$ $\mathrm{m} \cdot \mathrm{s}^{-1}$ and $4.53 \pm 0.33 \mathrm{~m} \cdot \mathrm{s}^{-1}$, respectively $(P<$ $0.05)$. The average running speeds at IC with the ground for the $\mathrm{BC}$ and $\mathrm{CL}$ were significantly different between the FAST and SLOW tasks. The 


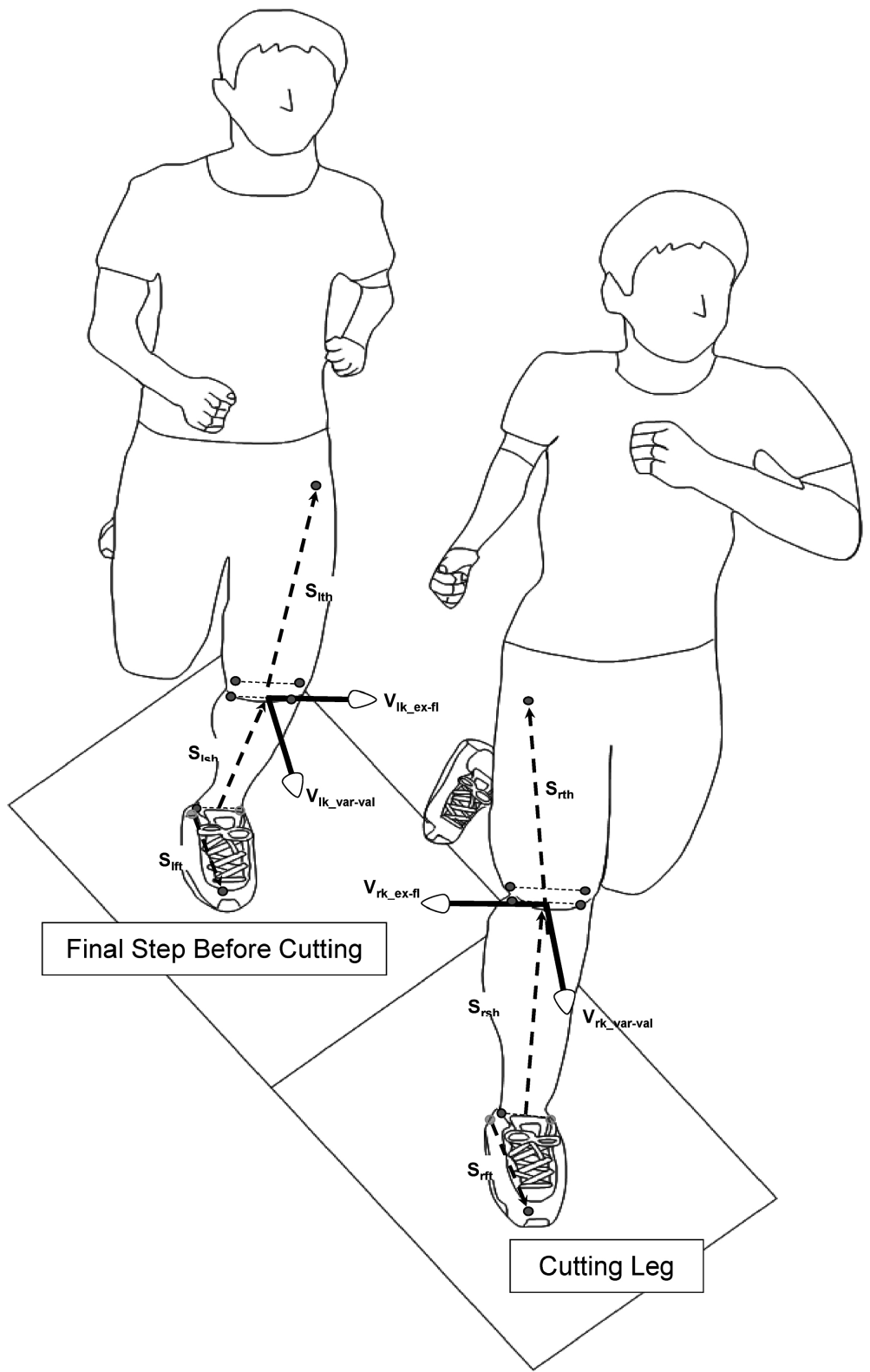

Figure 3 The joint coordinate systems for the flexion-extension axis of the knee joint $\left(\mathrm{V}_{\text {rk_ex-fl }}, \mathrm{V}_{\mathrm{lk} \text { _ex-fl }}\right)$ and the valgus-varus axis of the knee joint $\left(\mathrm{V}_{\text {rk_var-val }}, \mathrm{V}_{\mathrm{lk}_{\mathrm{k}} \text { var-val }}\right)$. The calculated joint moments were defined as the moments on the planes perpendicular to these axes.

Table 1 Measurements for the final step before cutting (BC) and cutting leg (CL) during the SLOW and FAST tasks

\begin{tabular}{|c|c|c|c|c|}
\hline & \multicolumn{2}{|c|}{ Final Step Before Cutting (Left Leg) } & \multicolumn{2}{|c|}{ Cutting Leg (Right Leg) } \\
\hline & SLOW (SD) & FAST (SD) & SLOW (SD) & FAST (SD) \\
\hline Running speed $\left(\mathrm{m} \cdot \mathrm{s}^{-1}\right)$ & $4.49 \quad(0.42)$ & $5.83(0.32)^{*}$ & $4.53 \quad(0.33)$ & $5.51(0.32)^{*}$ \\
\hline Duration (s) & $0.233(0.014)$ & $0.195(0.017)^{*}$ & $0.235(0.017)$ & $0.206(0.021)^{*}$ \\
\hline Impulse of GRFy $\left(\mathrm{Ns} \cdot \mathrm{kg}^{-1}\right)$ & $0.12 \quad(0.27)$ & $0.54 \quad(0.27)^{*}$ & $0.19 \quad(0.06)$ & $0.22 \quad(0.06)$ \\
\hline
\end{tabular}

*, significant difference between the SLOW and FAST tasks, $P<0.05$.

average durations of the $\mathrm{BC}$ and $\mathrm{CL}$ foot contacts were significantly shorter during the FAST task than during the SLOW task (FAST: $0.195 \pm 0.017 \mathrm{~s}$ vs.
SLOW: $0.233 \pm 0.014 \mathrm{~s}, P<0.05$, and FAST: 0.206 $\pm 0.021 \mathrm{~s}$ vs. SLOW: $0.235 \pm 0.017 \mathrm{~s}, P<0.05$, respectively) (Table 1). 

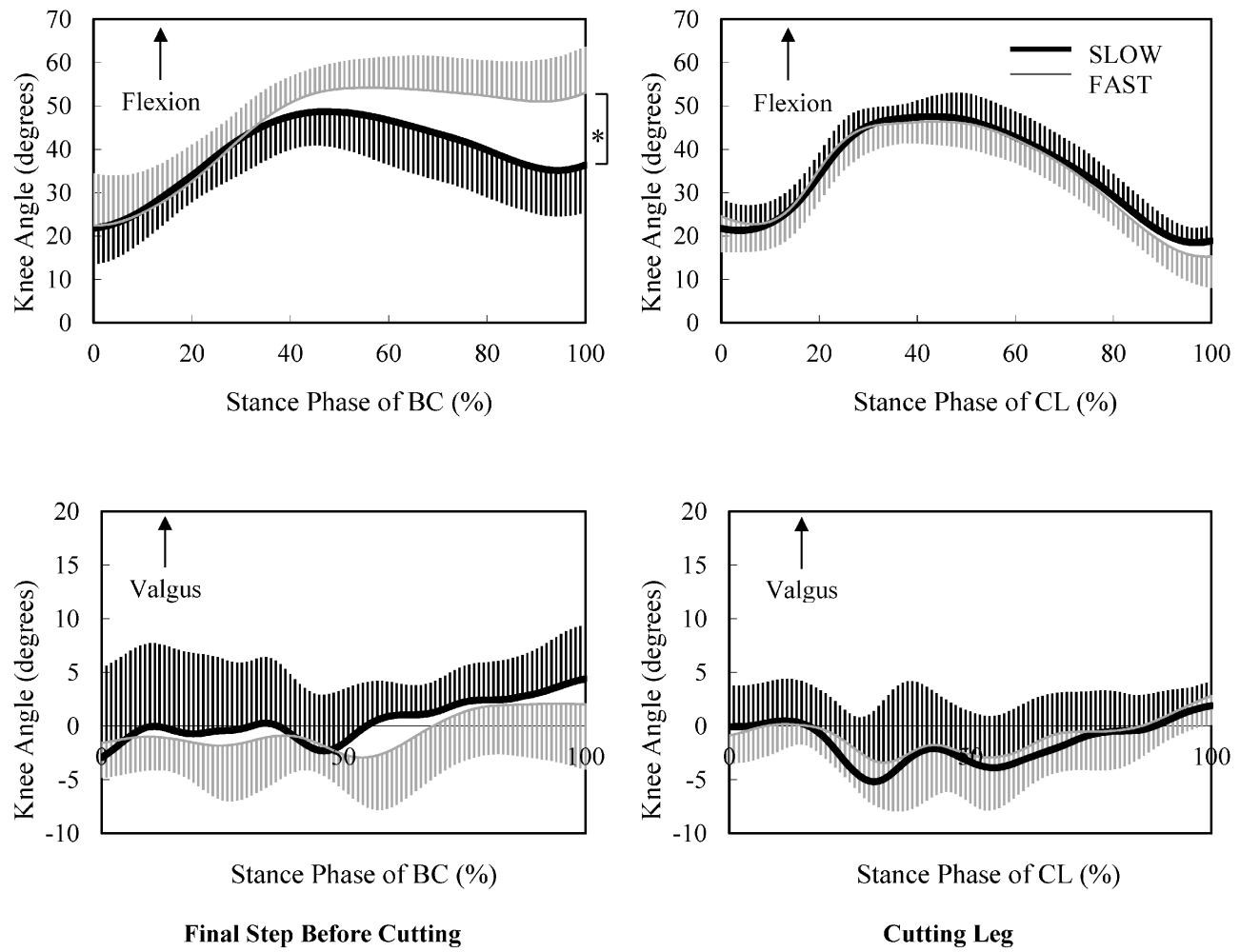

Final Step Before Cutting

Cutting Leg

Figure 4 Average time-curves, with standard deviations (SD), for the knee joint kinematics during the stance phase for the step before cutting (BC) and the cutting leg (CL). The thick solid line represents the SLOW task and the thin solid line represents the FAST task. *, significant difference between the FAST task and the SLOW task, $P<0.05$.
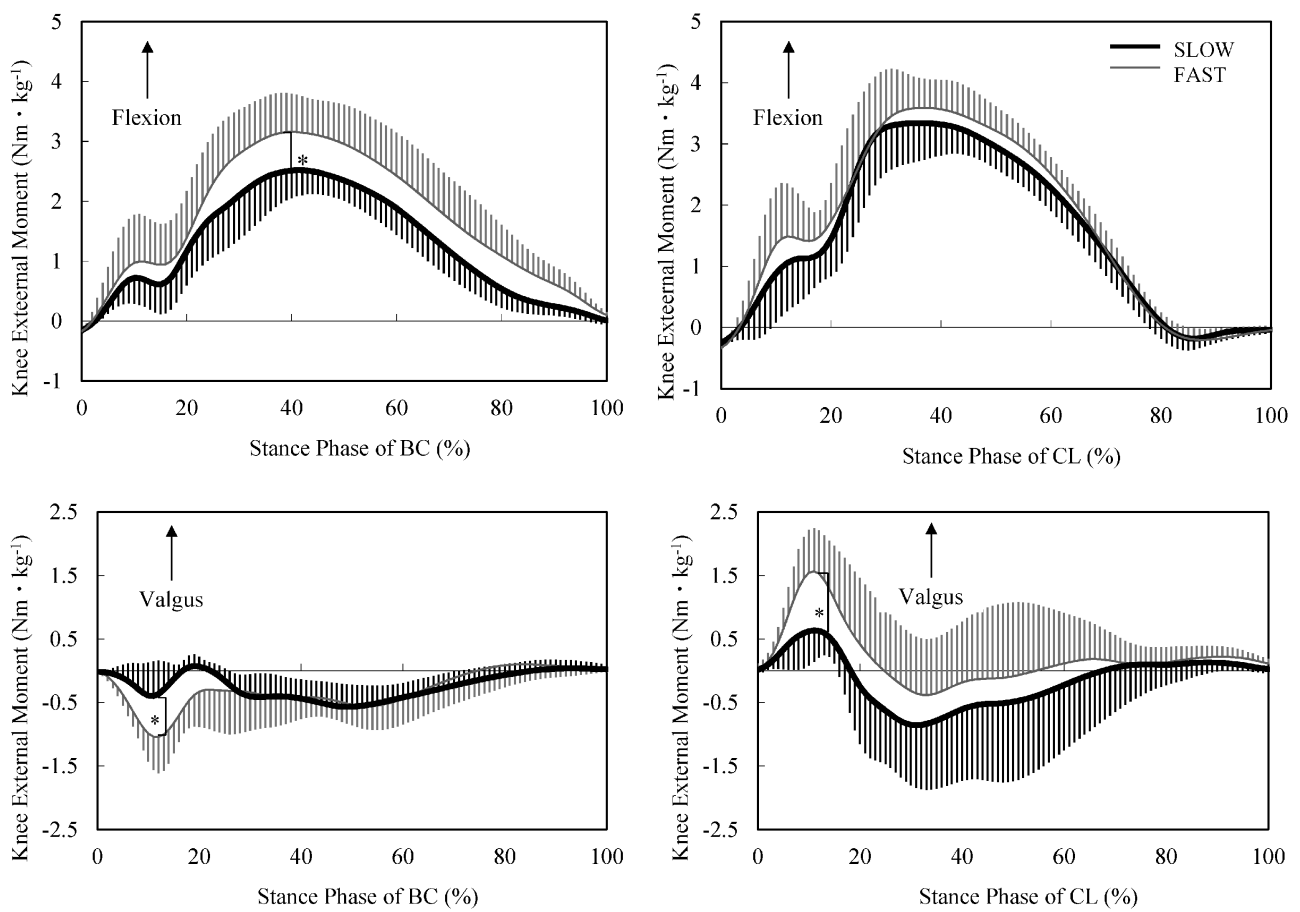

Final Step Before Cutting

Cutting Leg

Figure 5 Average time-curves, with standard deviations (SD), for the external moments acting on the knee during the stance phase for the step before cutting $(\mathrm{BC})$ and the cutting leg $(\mathrm{CL})$. The thick solid line represents the SLOW task and the thin solid line represents the FAST task. ${ }^{*}$, significant difference between the FAST task and the SLOW task, $P<0.05$. 
The average $\mathrm{BC} \mathrm{GRF}_{\mathrm{y}}$ impulse was significantly larger during the FAST task than during the SLOW task $\left(0.54 \pm 0.27 \mathrm{Ns} \cdot \mathrm{kg}^{-1}\right.$ vs. $0.12 \pm 0.27 \mathrm{Ns} \cdot \mathrm{kg}^{-1}$, $P<0.05)$. However, the $\mathrm{GRF}_{\mathrm{y}}$ average impulse of the CL during the deceleration phase did not significantly differ between the FAST and SLOW tasks $\left(0.22 \pm 0.06 \mathrm{Ns} \cdot \mathrm{kg}^{-1}\right.$ vs. $\left.0.19 \pm 0.06 \mathrm{Ns} \cdot \mathrm{kg}^{-1}\right)$ (Table 1).

Figure 4 shows the comparative results of the BC and CL knee joint angles between the FAST and SLOW tasks; the peak angles did not differ significantly, based on the movement speed. However, the average $\mathrm{BC}$ flexion angle of the knee joint at toeoff from the ground was significantly greater during the FAST task than during the SLOW task $\left(53.0^{\circ} \pm\right.$ $10.6^{\circ}$ vs. $36.4^{\circ} \pm 10.8^{\circ}, P<0.05$ ) (Figure 4).

Figure 5 shows the comparative results of the $\mathrm{BC}$ and $\mathrm{CL}$ external knee joint moment between the FAST and SLOW tasks. The peak external flexion moment of the BC knee joint was significantly larger during the FAST task than during the SLOW task $\left(3.16 \pm 0.64 \mathrm{Nm} \cdot \mathrm{kg}^{-1}\right.$ vs. $2.69 \pm 0.42 \mathrm{Nm} \cdot \mathrm{kg}^{-1}$, $P<0.05)$; the peak external varus moment during the first half of the BC stance was significantly larger during the FAST task than during the SLOW task $\left(1.22 \pm 0.54 \mathrm{Nm} \cdot \mathrm{kg}^{-1}\right.$ vs. $0.52 \pm 0.50 \mathrm{Nm} \cdot \mathrm{kg}^{-1}$, $P<0.05)$. The peak external flexion moment of the CL knee joint did not significantly differ between the two tasks. However, the peak external valgus moment during the first half of the CL stance was significantly larger during the FAST task than during the SLOW task $\left(1.85 \pm 0.56 \mathrm{Nm} \cdot \mathrm{kg}^{-1}\right.$ vs. $0.96 \pm$ $\left.0.57 \mathrm{Nm} \cdot \mathrm{kg}^{-1}, P<0.05\right)$ (Figure 5).

\section{Discussion}

This study investigated the adjustment of the BC movement and quantified the angles and moments applied to the $\mathrm{CL}$ and $\mathrm{BC}$ knee joints during the sidestep cut at both slow and fast speeds. We had hypothesized that the preparatory strategy during the final step prior to the direction change would decrease the load applied to the CL knee joint. We observed that the runners prepared to make the sidestep cut at the time of the $\mathrm{BC}$ foot contact rather than at the time of the CL foot contact in response to an increased running speed. This preparatory strategy for a fast-speed sidestep cut was an effective strategy for decreasing the external load of the CL knee joint.
Besier et al. (2003) reported that when the cutting task occurs under preplanned conditions, the central nervous system is capable of scaling the CL muscle activation patterns to compensate for the increased external load. However, under unanticipated conditions, there appeared to be a mismatch between the muscle activation patterns and the external loads (1.5 times larger than the values under preplanned conditions) applied to the knee joint. Their report suggests that there is a larger external moment for the CL knee joint during the cutting task under unanticipated conditions than under preplanned conditions because the central nervous system does not provide optimal force control of the muscle groups. In the present study, the average impulse of the BC $\mathrm{GRF}_{\mathrm{y}}$ during the FAST task was significantly larger than that during the SLOW task, however, the average impulse of the CL GRF $\mathrm{G}_{\mathrm{y}}$ was not significantly larger during the two tasks, indicating the increased external load on the knee joint resulted in $\mathrm{BC}$ deceleration in the sidestep cut at the faster running speeds. These results suggest that preparatory deceleration during the $\mathrm{BC}$ motion in a fast-speed sidestep cut is an effective strategy for decreasing the external load on the CL knee joint.

$\mathrm{Yu}$ et al. (2006) suggested that a posteriorly directed GRF during landing would force the knee to flex, resulting in an internal extension moment of the knee joint. The associated quadriceps muscle contraction simultaneously causes proximal tibial anterior shear force. In the present study, large increases in the peak external flexion moment and the peak external varus moment of the $\mathrm{BC}$ knee joint were observed during the FAST task compared with the SLOW task. There was, however, no significant difference in the peak external flexion moment of the CL knee joint during the two tasks (Figure 5). Therefore, the runner likely performed a deceleration movement prior to the $\mathrm{CL}$ foot coming into contact with the ground.

The peak external valgus moment during the first half of the CL stance and the peak external flexion moment of the BC knee joint were significantly larger during the FAST task than during the SLOW task. Other authors (McLean et al., 2004b) have suggested that the sagittal plane loads of knee joint forces do not cause ACL injuries during sidestep cuts because the proximal tibial anterior shear force, alone, is insufficient to rupture the ACL (Woo et al., 1991). On the other hand, Markolf et al. (1995) 
reported that a combination of the proximal tibial anterior shear force and the external valgus moment generated 1.5-2.0 times larger ACL tensile forces than the proximal tibial anterior shear force, alone. In the present study, the peak external flexion moment of the BC knee joint during the FAST task was significantly larger than that during the SLOW task. However, the peak external flexion moment of the CL knee joint did not significantly differ between the FAST and SLOW tasks. The results of the present investigation suggest that the external flexion moment of the CL knee joint was reduced by the deceleration during the preparatory $\mathrm{BC}$ movement, though the large external valgus moment during the first half of the CL movement in the fast-speed sidestep cut was unavoidable. Thus, we concluded that the preparatory $\mathrm{BC}$ movement results in the avoidance of a combination of a large external valgus moment and a large internal CL knee extension moment.

A controlled study that accounts for unanticipated conditions could identify strategies for changing directions quickly using the sidestep cut. However, the sidestep cut during fast-speed running, under unanticipated conditions, is considered hazardous because the faster running speed causes a larger GRF during the stance phase (Munro et al., 1987), resulting in a large external moment on the lower leg. This study was limited to only preplanned conditions during the sidestep cut for the sake of safety, but it would be reasonable to consider that an unanticipated sidestep cut during high-speed running would result in a larger CL knee joint external moment.

In conclusion, under preplanned conditions, generating an internal extension moment of the CL knee joint to counteract the external moment of the braking force is less necessary because the runner has already almost completed deceleration during the preceding step. Therefore, a preparatory movement during the $\mathrm{BC}$ step, in a fast-speed sidestep cut, is an effective strategy for decreasing the external load applied to the CL knee joint.

\section{References}

Ae, M. (1996). Body segment inertia parameters for Japanese children and athletes. Jap. J. Sports Sci., 15: 155-162. (In Japanese)

Agel, J., Arendt, E. A., and Bershadsky, B. (2005). Anterior cruciate ligament injury in national collegiate athletic association basketball and soccer. Am. J. Sports Med., 33: 524-531. Andrews, J. G. (1974). Biomechanical analysis of human mo- tion. In Kinesiology IV (pp 32-42). Washington, DC: AAHPER

Besier, T. F., Lloyd, D. G., Ackland, T. R., and Cochrane, J. L. (2001b). Anticipatory effects on knee joint loading during running and cutting maneuvers. Med. Sci. Sports Exerc., 33: 1176-1181.

Besier, T. F., Lloyd, D. G., Cochrane, J. L., and Ackland, T. R. (2001a). External loading of the knee joint during running and cutting maneuvers. Med. Sci. Sports Exerc., 33: 1168-1175.

Besier, T. F., Lloyd, D. G., and Ackland, T. R. (2003). Muscle activation strategies at the knee during running and cutting maneuvers. Med. Sci. Sports Exerc., 35: 119-127.

Cerulli, G., Benoit, D. L., LaMontagne, M., Caraffa, A., and Liti, A. (2003). In vivo anterior cruciate ligament strain behaviour during a rapid deceleration movement: case report. Knee Surg. Sports Traumatol. Arthrosc., 11: 307-311.

Chappell, J. D., Herman, D. C., Knight, B. S., Kirkendall, D. T., Garrett, W. E., and Yu, B. (2005). Effect of fatigue on knee kinetics and kinematics in stop-jump tasks. Am. J. Sports Med., 33: 1022-1029.

Cowley, H. R., Ford, K. R., Myer, G. D., Kernozek, T. W., and Hewett, T. E. (2006). Differences in neuromuscular strategies between landing and cutting tasks in female basketball and soccer athletes. J. Athl. Train., 41: 67-73.

Dufek, J. S., and Bates, B. T. (1991). Biomechanical factors associated with injury during landing in jump sports. Sports Med., 12: 326-337.

Hewett, T. E., Myer, G. D., Ford, K. R., Heidt, R. S. Jr., Colosimo, A. J., McLean, S. G, van den Bogert, A. J., Paterno, M. V., and Succop, P. (2005). Biomechanical measures of neuromuscular control and valgus loading of the knee predict anterior cruciate ligament injury risk in female athletes: A prospective study. Am. J. Sports Med., 33: 492-501.

Hewett, T. E., Paterno, M. V., and Myer, G. D. (2002). Strategies for enhancing proprioception and neuromuscular control of the knee. Clin. Orthop. Relat. Res., 402: 76-94.

Kimura, K., and Sakurai, S. (2008). Effect of changing turn angle and running speed on cutting movement during sidestep cutting. Proceedings of the $26^{\text {th }}$ International Conference on Biomechanics in Sports, Jul 14-18, Seoul-Korea. Book of Abstract: 465.

Malinzak, R. A., Colby, S. M., Kirkendall, D. T., Yu, B., and Garrett, W. E. (2001). A comparison of knee joint motion patterns between men and women in selected athletic tasks. Clin. Biomech., 16: 438-445.

Markolf, K. L., Burchfield, D. M., Shapiro, M. M., Shepard, M. F., Finerman, G. A., and Slauterbeck, J. L. (1995). Combined knee loading states that generate high anterior cruciate ligament forces. J. Orthop Res., 13: 930-935.

McLean, S. G., Huang, X., Su, A., and van den Bogert, A. J. (2004a). Sagittal plane biomechanics cannot injure the ACL during sidestep cutting. Clin. Biomech., 19: 828-838.

McLean, S. G., Lipfert, S. W., and van den Bogert, A. J. (2004b). Effect of gender and defensive opponent on the biomechanics of sidestep cutting. Med. Sci. Sports Exerc., 36: 1008-1016.

Munro, C. F., Miller, D. I., and Fuglevand, A. J. (1987). Ground reaction forces in running: a reexamination. J. Biomech., 20: 147-155.

Olsen, O. E., Myklebust, G., Engebretsen, L., and Bahr, R. (2004). Injury mechanisms for anterior cruciate ligament injuries in team handball: A systematic video analysis. Am. J. 
Sports Med., 32: 1002-1012.

Pflum, M. A., Shelburne, K. B., Torry, M. R., Decker, M. J., and Pandy, M. G. (2004). Model prediction of anterior cruciate ligament force during drop-landings. Med. Sci. Sports Exerc., 36: 1949-1958.

Wojtys, E. M., Huston, L. J., Schock, H. J., Boylan, J. P., and Ashton-Miller, J. A. (2003). Gender differences in muscular protection of the knee in torsion in size-matched athletes. J. Bone Joint Surg. Am., 85-A: 782-789.

Woo, S. L., Hollis, J. M., Adams, D. J., Lyon, R. M., and Takai, S. (1991). Tensile properties of the human femur-anterior cruciate ligament-tibia complex. The effects of specimen age and orientation. Am. J. Sports Med., 19: 217-225.

Yu, B., Gabriel, D., Noble, L., and Kai-Nan, A. (1999). Estimate of the optimal cutoff frequency for the Butterworth lowpass digital filter. J. Appl. Biomech., 15: 318-329.

$\mathrm{Yu}$, B., Jonathon, C. J., and Garrett, W. E. (2006). Comment: Effect of fatigue on knee kinetics and kinematics in stop-jump tasks. Am. J. Sports Med., 34: 312-315.

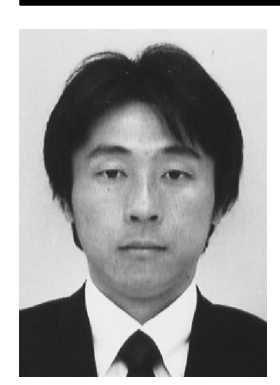

Name:

Kenji Kimura

Affiliation:

Graduate School of Health and Sport Sciences, Chukyo University

Address:

101 Tokodachi, Kaizu-cho, Toyota, Aichi, 470-0390 Japan

Brief history:

2007-Assistant, Graduate School of Health and Sport Sciences, Chukyo University

2010-Office staff, Physical Education Center, Nanzan University Membership in Learned Societies:

- Japanese Society of Biomechanics

-Japan Society of Physical Education, Health and Sport Sciences

-International Society of Biomechanics in Sports 